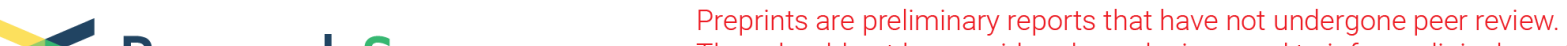 Research Square
or referenced by the media as validated information.
}

\section{Spike protein up-regulates inflammatory axis of both thromboinflammation and leukotriene in severe COVID-19}

\section{Xiaopeng Tang}

1 Key Laboratory of Animal Models and Human Disease Mechanisms of Chinese Academy of Sciences/Key Laboratory of Bioactive Peptides of Yunnan Province, Kunming Institute of Zoology, Kunming 650223, Yunnan, China;

\section{Mingqian Fang}

1Key Laboratory of Animal Models and Human Disease Mechanisms of Chinese Academy of Sciences/Key Laboratory of Bioactive Peptides of Yunnan Province, Kunming Institute of Zoology, Kunming 650223, Yunnan, China;

\section{Juan Zhang}

1Key Laboratory of Animal Models and Human Disease Mechanisms of Chinese Academy of Sciences/Key Laboratory of Bioactive Peptides of Yunnan Province, Kunming Institute of Zoology, Kunming 650223, Yunnan, China;

\section{Zhiyi Liao}

1Key Laboratory of Animal Models and Human Disease Mechanisms of Chinese Academy of Sciences/Key Laboratory of Bioactive Peptides of Yunnan Province, Kunming Institute of Zoology, Kunming 650223, Yunnan, China;

\section{Ruomei Cheng}

1Key Laboratory of Animal Models and Human Disease Mechanisms of Chinese Academy of Sciences/Key Laboratory of Bioactive Peptides of Yunnan Province, Kunming Institute of Zoology, Kunming 650223, Yunnan, China;

\section{Kuanhong Xu}

Hefei National Laboratory for Physical Sciences at the Microscale and School of Life Sciences, University of Science and Technology of China, Hefei 230027, Anhui, China;

\section{Hongwen Zhao}

Southwest Hospital, Third Military Medical University (Army Medical University). 29 Gaotanyan Street, Shapingba District, Chongqing, 400038, P. R. China;

\section{Jing Wang}

Department of Laboratory Diagnosis. Chongqing Public Health Medical Center, Public Health Hospital of Southwest University, 109 Baoyu Rd. Shapingba District, Chongqing, 400038, P. R. China;

\section{Zhaoxia Tan}


Southwest Hospital, Third Military Medical University (Army Medical University). 29 Gaotanyan Street, Shapingba District, Chongqing, 400038, P. R. China;

\section{Gan Wang}

Key Laboratory of Animal Models and Human Disease Mechanisms of Chinese Academy of Sciences/Key Laboratory of Bioactive Peptides of Yunnan Province, Kunming Institute of Zoology, Kunming 650223, Yunnan, China;

\section{Peter M Kamau}

Key Laboratory of Animal Models and Human Disease Mechanisms of Chinese Academy of Sciences/Key Laboratory of Bioactive Peptides of Yunnan Province, Kunming Institute of Zoology, Kunming 650223, Yunnan, China;

\section{Zhiye Zhang}

Key Laboratory of Animal Models and Human Disease Mechanisms of Chinese Academy of Sciences/Key Laboratory of Bioactive Peptides of Yunnan Province, Kunming Institute of Zoology, Kunming 650223, Yunnan, China;

\section{James Mwangi}

Key Laboratory of Animal Models and Human Disease Mechanisms of Chinese Academy of Sciences/Key Laboratory of Bioactive Peptides of Yunnan Province, Kunming Institute of Zoology, Kunming 650223, Yunnan, China;

\section{Qiumin Lu}

Key Laboratory of Animal Models and Human Disease Mechanisms of Chinese Academy of Sciences/Key Laboratory of Bioactive Peptides of Yunnan Province, Kunming Institute of Zoology, Kunming 650223, Yunnan, China;

\section{Guohong Deng ( $\nabla$ orgh_deng@hotmail.com )}

Southwest Hospital, Third Military Medical University (Army Medical University). 29 Gaotanyan Street, Shapingba District, Chongqing, 400038, P. R. China;

\section{Ren Lai ( $\sim$ rlai@mail.kiz.ac.cn )}

Southwest Hospital, Third Military Medical University (Army Medical University). 29 Gaotanyan Street, Shapingba District, Chongqing, 400038, P. R. China;

\section{Research Article}

Keywords: COVID-19, Hypercytokinemia, fibrinogen, leukotriene-A4 hydrolase (LTA4H)

Posted Date: June 3rd, 2020

DOI: https://doi.org/10.21203/rs.3.rs-33171/v1

License: (c) (i) This work is licensed under a Creative Commons Attribution 4.0 International License. Read Full License 


\section{Abstract}

Hypercytokinemia is a critically fatal factor in COVID-19. However, underlying pathogenic mechanisms are unknown. Here we show that fibrinogen and leukotriene-A4 hydrolase (LTA4H), two of the most potent inflammatory contributors, are elevated by 67.7 and astonishing $227.7 \%$ in the plasma of patients infected by SARS-CoV-2 and admitted to intensive care unit in comparison with healthy control, respectively. Conversely, transferrin identified as a fibrinogen immobilizer in our recent work and Spink6 are down-regulated by 40.3 and $25.9 \%$, respectively. Furthermore, we identify Spink6 as the first endogenous inhibitor of LTA4H, a pro-inflammatory enzyme catalyzing final and rating limited step in biosynthesis of leukotriene-B4 that is an extremely inflammatory mediator and a target to design superior anti-inflammatory drugs. Additionally, virus Spike protein is found to evoke LTA4H and fibrinogen expression in vivo. Collectively, these findings identify the imbalance between inflammatory drivers and antagonists, which likely contributes to hypercytokinemia in COVID-19. Spink6 may have superior antiinflammatory function because it specifically targets epoxide hydrolase of LTA4H to inhibit leukotriene-B4 biosynthesis without effecting LTA4H's aminopeptidase activity.

\section{Introduction}

In December 2019, the first pneumonia case caused by the infection of Severe Acute Respiratory Syndrome Coronavirus 2 (SARS-CoV-2 or COVID-2019) was reported ${ }^{1-3}$. COVID-2019 outbreak has since rapidly spread to other places in $\mathrm{China}^{4}$, as well as other countries around the world. As of April 6, 2020, 1288592 cases of COVID-19 have been confirmed and 70446 cases died worldwide, carrying a mortality of approximately $5.467 \%$, compared with a mortality rate of less than $1 \%$ from influenza. Accumulating evidence indicates that a subgroup of patients with severe COVID-19 have a cytokine storm syndrome (hypercytokinemia) to cause hyperinflammation. On 11 March, 2020, world health organization (WHO) characterized SARS-CoV-2 as a pandemic. This is the first pandemic caused by a coronavirus ${ }^{6}$. Unfortunately, to date, there is no vaccine or antiviral treatment for this coronavirus.

As other pathogenic human coronavirus such as severe acute respiratory syndrome CoV (SARS-CoV) and Middle East respiratory syndrome CoV (MERS-CoV) ${ }^{7}$, SARS-CoV-2 infects lower respiratory tract to cause lung immunopathology and lead to deleterious clinical manifestations such as severe pneumonia, fatal acute lung injury and acute respiratory distress syndrome, consequently resulting in high morbidity and mortality ${ }^{8 \mathrm{X}}$. The severity of clinical manifestations is often associated with dysregulated immune response and elevated proinflammatory cytokine/chemokine responses that possibly progress to a hypercytokinemia. All those observations strongly suggest that immunopathological events play crucial roles to cause fatal pneumonia after SARS-CoV-2 infections. However, the underlying molecular events causing the hypercytokinemia are unknown.

In this study, we investigate the immunopathology mechanisms after SARS-CoV-2 infection. We find that: 1) the virus Spike protein promotes LTA4H expression; 2) Spink6 is the first identified endogenous inhibitor of LTA4H, one of the most potent inflammatory driver; 3) significant imbalance between two of 
the most potent inflammatory drivers (fibrinogen and LTA4H) and their antagonists (transferrin and Spink6) possibly causes hypercytokinemia in COVID-19.

\section{Results}

\section{Fibrinogen and its endogenous immobilizer transferrin are up- and down-regulated in the plasma of patients infected by SARS-CoV-2, respectively}

As one of the most potent inflammatory mediators, fibrinogen has powerful role in driving inflammatory responses and can be up-regulated by virus infection ${ }^{10-12}$. As illustrated in Figure $1 \mathrm{~A}$ and Table $\mathrm{S} 1$ and 2 , blood routine examination showed that mean plasma fibrinogen concentration in ICU $(4.868 \mathrm{mg} / \mathrm{ml})$ (S$\mathrm{SC}, \mathrm{n}=22$; male 12; female 10; age: $36-77$ years) and in non-ICU $(4.109 \mathrm{mg} / \mathrm{ml})$ patients (MM, $\mathrm{n}=40$; male 20; female 20; age: $10-73$ years) was much higher than that in control healthy $(2.903 \mathrm{mg} / \mathrm{ml})(\mathrm{HC}$, $\mathrm{n}=37$; male 19; female 18; age: 28-56 years). Recently, we have demonstrated that the iron transporter transferrin is an immobilizer of fibrinogen by binding to fibrinogen with a molecular ratio of $4: 1^{13}$. We next checked transferrin concentration in the plasma of the patients. Mean transferrin concentration $(1.443 \mathrm{mg} / \mathrm{ml})$ in the plasma of patients infected by SARS-CoV -2 who had been admitted to ICU $(n=20$; male 12; female 8; age: $36-77$ years) was significantly lower than that in non-ICU patients $(1.854 \mathrm{mg} / \mathrm{ml})$ $(\mathrm{MM}, \mathrm{n}=43$; male 23; female 20; age: $10-73$ years) and that in healthy control $(2.417 \mathrm{mg} / \mathrm{ml})(\mathrm{HC}, \mathrm{n}=22$; male 14; female 8; age: 28-56 years) (Figure 1B and Table S1 and 3).

After a $24-48 \mathrm{~h}$ in vivo administration $(40 \mathrm{~g} / \mathrm{kg})$, the virus Spike protein significantly up-regulated fibrinogen in mice (Figure 1C), further confirming that SARS-CoV-2 infection is able to evoke fibrinogen expression. The increase of inflammatory mediator fibrinogen and the decrease of its endogenous immobilizer transferrin in the plasma of patients infected by SARS-CoV-2 likely produce the increased tendency for inflammation.

\section{The serine protease inhibitor-like protein Spink6 is identified as the first endogenous inhibitor of LTA4H}

As a ubiquitously expressed proinflammatory enzyme, LTA4H has two opposing roles in inflammation regulation including the biosynthesis of inflammatory mediator leukotriene-B4 (LTB4) and antiinflammation by degrading and inactivating the chemotactic tripeptide PGP ${ }^{13-15}$. None of LTA4H's endogenous inhibitor has been identified. Surface plasmon resonance (SPR) analysis revealed that Spink6 directly interacted with LTA4H (Figure 2A), and the association rate constant (Ka),, dissociation rate constant $(K d)$," and equilibrium dissociation constant $K D)$ values for the interaction between Spink6 and LTA4H were $2.8 \times 10^{5} \mathrm{M}^{-1} \mathrm{~s}^{-1}, 1.3 \times 10^{-4} \mathrm{~s}^{-1}$, and $0.45 \mathrm{nM}$ (Figure 2A). We found here that Spink6, which is as a serine protease inhibitor with 57 amino acid residues ${ }^{17}$, selectively inhibited the epoxide 
hydrolase function of LTA4H (Figure 2B-D) to inhibit LTA4 hydrolysis and finally block the formation LTB4, an important pro-inflammatory lipid mediator. However, Spink6 had no effect on the aminopeptidase function of LTA4H (Figure 2E), suggesting that Spink6 does not impair the anti-inflammatory function of LTA4H.

\section{LTA4H and Spink6 are up- and down-regulated in the plasma of COVID-19 patients, respectively and Spike protein induces LTA4H expression}

LTA4H plays a key role in catalyzing final and rating limited step in biosynthesis of leukotriene-B4, which has been implicated in many acute and chronic inflammatory diseases ${ }^{14,15,17-21}$. The concentration of LTA4H was investigated in the plasma of the patients. As illustrated in Figure $3 \mathrm{~A}$ and Table $\mathrm{S} 1$ and 4 , the mean plasma LTA4H concentration in ICU patients $(240 \mathrm{ng} / \mathrm{ml})(\mathrm{S}-\mathrm{SC}, \mathrm{n}=22$; male 12; female 10; age: 36-77 years) was much higher than that non-ICU $(88.55 \mathrm{ng} / \mathrm{ml})$ patients $(M M, n=37$; male 23; female 14; age: $10-73$ years) and in control healthy $(73.24 \mathrm{ng} / \mathrm{ml})(\mathrm{HC}, \mathrm{n}=18$; male 10 ; female 8 ; age: $28-56$ years). Spink6 has been identified an endogenous inhibitor of LTA4H as above. Mean concentration of Spink6 in the plasma of ICU (15.51 ng/ml) (S-SC, $\mathrm{n}=21$; male 13; female 8; age: 36-77 years) and nonICU (15.38 ng/ml) (MM, n = 37; male 17; female 20; age: 10-73 years) patients infected by SARS-CoV-2 was down-regulated in comparison with that in healthy control $(20.93 \mathrm{ng} / \mathrm{ml})(\mathrm{HC}, \mathrm{n}=18$; male 10; female 8; age: 28-56 years) (Figure 3B and Table S1 and 5). LTA4H's up-regulation and its endogenous inhibitor Spink6's down-reregulationin the plasma of patients infected by SARS-CoV-2 likely increase the production of leukotriene-B4, an extremely inflammatory mediator.

In order to investigate the mechanism to induce LTA4H's up-regulation in the patients, we intravenously administrated the virus Spike protein to mice and test it's effect on LTA4H expression in vivo. As illustrated in Figure 3C, compared with the basic LTA4H concentration of $2.2 \mathrm{~g} / \mathrm{ml}$ in mouse plasma, the LTA4H concentration was increased to 3.2 and $4.3 \mathrm{~g} / \mathrm{ml}$ at day 1 and day 2 after the Spike protein administration $(40 \mathrm{~g} / \mathrm{kg})$, respectively, further confirming that SARS-CoV-2 infection is able to evoke LTA4H expression.

\section{Transferrin and Spink6 inhibit TNF- secretion induced by fibrinogen and LTA4H, respectively}

As two of the most potent inflammatory drivers ${ }^{10-16}$, fibrinogen and LTA4H have ability to drive inflammation by directly or indirectly promoting inflammatory cytokines secretion. Considering that significantly elevated concentrations of fibrinogen and LTA4H were found in the plasma of patients infected by SARS-CoV-2 and in the mouse plasma treated by the virus Spike protein, we tested if transferrin and Spink6 have ability to inhibit inflammatory cytokine secretion induced by fibrinogen and LTA4H. As illustrated in Figure 4A, fibrinogen ( $1 \mathrm{mg} / \mathrm{ml}, 3 \mathrm{M})$ significantly induced TNF- secretion in 
mouse macrophage cells of RAW264.7, while transferrin inhibited the cytokine secretion in a dosedependent manner. Unexpectedly, TNF- secretion induced by fibrinogen was also inhibited by Spink6 (Figure 4B), suggesting that thromboinflammation induced by fibrinogen is associated with leukotriene inflammatory signaling. In addition, as expectedly, the virus Spike protein $(40 \mathrm{~g} / \mathrm{ml}, 0.5 \mathrm{M})$ up-regulated TNF- expression in the RAW264.7 cells while Spink6 inhibited the up-regulation (Figure 4C). Given that LTB4 was associated with pulmonary disorders and neutrophil migration in lipopolysaccharide (LPS)induced acute lung injury 22, 23, we investigated if Spink6 has effect on TNF- expression promoted by LPS in human monocytic cell (THP-1). As illustrated in Figure 4D, Spink6 (40 nM) inhibited TNF- secretion induced by both virus Spike protein $(40 \mathrm{~g} / \mathrm{ml}, 0.5 \mathrm{M})$ and LPS $(1 \mathrm{~g} / \mathrm{ml})$ in the THP- 1 cells.

\section{Methods}

\section{Collection of human samples}

Thirty seven healthy individuals were from staffs at Southwest Hospital (Army Medical University) and Chongqing Public Health Medical Center (CPHMC), Chongqing, China, 65 COVID-19 patients were from CPHMC (22 severe patients admitted to intensive care unit (ICU) and 43 non-severe patients). This study was approved by the ethics committee of CPHMC (2020-002-01KY) and conducted in accordance with Declaration of Helsinki principles. Residual serum samples after laboratory diagnosis were used to test the fibrinogen, transferrin, leukotriene-A4 hydrolase (LTA4H) and serine peptidase inhibitor Kazal type 6 (Spink6) by enzyme-linked immunosorbent assay, and the requirement for informed consent was waived.

\section{Animals and ethics statement}

All animal experiments were approved by the Animal Care and Use Committee of the Kunming Institute of Zoology (SMKX-202003) and conformed to the US National Institutes of Health's Guide for the Care and Use of Laboratory Animals (National Academies Press, 8th Edition, 2011). Specific-pathogen-free (SPF) C57BL/6J mice (male, 8 weeks old, 10 back crosses) were purchased from the Institute of Laboratory Animal Sciences, Chinese Academy of Medical Sciences. All mice were housed under a $12 \mathrm{~h} \mathrm{light}-12 \mathrm{~h}$ dark cycle at $24^{\circ} \mathrm{C}$ and tested at 10 weeks of age.

Enzyme-linked immunosorbent assay (ELISA)

Cytokine in the sample (cell supernatant) were measured using mouse TNF- $\alpha$ ELISA kit (DKW12-2720096, Dakewe Biotech, China) and human TNF-a ELISA kit (DKW12-1720-096, Dakewe Biotech, China) according to the manufacturers' instructions. Concentrations of fibrinogen and LTA4H in plasma of mice stimulated by Spike were tested using a mouse fibrinogen ELISA kit (SEA193Mu, Uscn, China) and a LTA4H ELISA kit (orb440632, Biorbyt, China), respectively.

\section{Stimulation assays}


Mice were intravenously injected with Spike (40 $\mu \mathrm{g} / \mathrm{kg} ; 40069-\mathrm{V} 08 \mathrm{~B}$, Sino Biological, China), and the plasma from different groups of mice after stimulation of $0,12,24$, and $48 \mathrm{~h}$, respectively, was extracted and the concentrations of fibrinogen and LTA4H were tested using a mouse fibrinogen ELISA kit and a LTA4H ELISA kit, respectively, as described above.

\section{Surface plasmon resonance (SPR) analysis}

BIAcore 2000 (GE, USA) was used to analyze the interaction between Spink6 and LTA4H. LTA4H was first diluted $(20 \mu \mathrm{g} / \mathrm{ml})$ with $200 \mu \mathrm{l}$ of sodium acetate $(10 \mathrm{mM}$, pH5), with the LTA4H solution then flowed across the activated surface by NHS (N-hydroxysuccinimide) and EDC (1-ethyl-3-[3dimethylaminopropyl] carbodiimide hydrochloride) of the CM5 sensor chip at a flow rate of $5 \mu \mathrm{l} / \mathrm{min}$ to couple with a CM5 sensor chip (BR100012, GE, USA) to a 1000-target response value (RU). The remaining activated sites on the CM5 sensor chip were blocked by $75 \mu$ l of ethanolamine ( $1 \mathrm{M}, \mathrm{pH} 8.5)$. Different concentrations of Spink6 (100, 200, 400, and 800 nM; orb528986, Biorbyt, China) in Tris buffer (20 mM, $\mathrm{pH}$ 7.4) were applied to analyze interactions with LTA4H on the surface of the CM5 sensor chip at a flow rate of $20 \mu \mathrm{l} / \mathrm{min}$. The purity of all purchased proteins was greater than $98 \%$. The equilibrium dissociation constant $(K D)$ for binding, as well as the association $(K a)$ and dissociation $(K d)$ rate constants, were determined by the BIA evaluation program (GE, USA).

\section{Assay of Spink6 on LTA4H}

The epoxide hydrolase activity of LTA4H was assayed by reverse phase high performance liquid chromatography (RP-HPLC) and ELISA. Firstly, LTA4 methyl ester (10 $\mu \mathrm{g}, 20010-500$, Cayman, USA) was hydrolyzed to LTA4 by alkaline hydrolysis buffer as per the manufacturer's protocol. Different concentrations $(0.4,2$ and $10 \mu \mathrm{M})$ of Spink6 were incubated with LTA4H (100 nM, 10007817, Cayman, USA) in $40 \mu$ l of Tris buffer (100 mM, pH 7.4) for 5 min at $37^{\circ} \mathrm{C}$. Secondly, LTA4 solution (10 $\left.\mu \mathrm{l}\right)$ described above was added to a final concentration of $50 \mu \mathrm{M}$, and the reaction mixture was incubated for 20 min at $37^{\circ} \mathrm{C}$. At last, the reaction was stopped by addition of 1 volume of methanol. The samples were analyzed by RP-HPLC using C18 column ( $30 \mathrm{~cm} \times 0.46 \mathrm{~cm}$, Hypersil BDS, USA). The elution buffer was a mixture of methanol/water/acetic acid (70/30/0.0025; v/v/v) and the absorbance was monitored at $270 \mathrm{~nm}$. The experimental results calculate the LTB4 generation rate based on the peak area integration value.

The effect of Spink6 on the activity of LTA4H aminopeptidase was detected by ninhydrin color development method. LTA4H $(0.5 \mu \mathrm{M})$ was mixed with different concentrations of Spink6. After incubating at $37^{\circ} \mathrm{C}$ for $25 \mathrm{~min}, \mathrm{PGP}$ (N-acetyl-Pro-Gly-Pro, 11189, Cayman, UK) was added and reacted at $37^{\circ} \mathrm{C}$ for $20 \mathrm{~min}$. The volume of the reaction solution was diluted 10 times (the final volume was $200 \mu \mathrm{l}$ ), and an equal volume of ninhydrin solution $(25 \mathrm{mg}$ of ninhydrin dissolved in $6 \mathrm{M}$ phosphoric acid in acetic acid at $70{ }^{\circ} \mathrm{C}$ ) was added. The mixture was reacted at $100{ }^{\circ} \mathrm{C}$ for $45 \mathrm{~min}$, after cooling, it was extracted with $400 \mu \mathrm{l}$ of toluene to transfer all the pigment to the toluene layer, and the absorbance was measured at $520 \mathrm{~nm}$. 


\section{Effects of transferrin or Spink6 on cytokines release}

RAW264.7 cells were seeded into 24 -well plates at $4 \times 10^{5}$ cells/well and maintained in RPMI 1640 medium containing $10 \%$ fetal bovine serum. After $12 \mathrm{~h}$ of adherence, serum-free medium was changed and cultured for $6 \mathrm{~h}$. Cells were incubated with fibrinogen ( $1 \mathrm{mg} / \mathrm{ml}$; F3879-100MG, Sigma, USA) and transferrin $(0.05,0.5$, and $5 \mu \mathrm{M}, \mathrm{T} 4382$, Sigma, USA) or Spink6 $(10,20$, and $40 \mathrm{nM})$ for $16 \mathrm{~h}$. Supernatant levels of TNF-a was measured using ELISA kit according to the manufacturers' instructions.

The effects of Spink6 on cytokine release of RAW264.7 cells induced by Spike protein was performed as the method described above. Human monocytic cell line (THP-1 cells) were seeded into 96-well plates at $4 \times 10^{4}$ cells/well and incubated with $100 \mathrm{ng} / \mathrm{ml} \mathrm{PMA} \mathrm{(S1819,} \mathrm{Beyotime,} \mathrm{China)} \mathrm{in} \mathrm{RPMI} 1640$ medium containing $10 \%$ fetal bovine serum for $24 \mathrm{~h}$. The medium was removed and changed to complete medium without PMA for another $24 \mathrm{~h}$. Different concentrations of LPS $(1 \mu \mathrm{g} / \mathrm{ml} ; \mathrm{L} 2630-10 M G$, Sigma, USA), Spike $(40 \mu \mathrm{g} / \mathrm{ml})$ and Spink6 (40 $\mathrm{nM})$ were then added and incubated with the cells for $12 \mathrm{~h}$ at 37 ' $\mathrm{C}$. TNF-a levels in the cell supernatant were tested using the ELISA kits according to the manufacturers' instructions.

\section{Statistical analysis}

The data obtained from independent experiments are presented as means \pm SD. All statistical analyses were two-tailed with $95 \%$ confidence intervals $(\mathrm{Cl})$. Kolmogorov-Smirnov test (K-S test) was used in the analysis of normal distribution, and data were then analyzed using one-way ANOVA with post hoc Dunnett adjustment for $p$ values. If only 2 groups were compared, unpaired t-test was applied. In all statistical analyses, significance was set at $p<0.05$. Analyses were done with SPSS software (v22.0) and GraphPad Prism (v5.0).

\section{Discussion}

This study showed that two of the most potent inflammatory drivers (fibrinogen and LTA4H) were significantly up-regulated, while their antagonists (transferrin and Spink6) were significantly downregulated in the plasma of patients infected by SARS-CoV-2. The drivers' up-regulation and agonists' down-regulation are positively and negatively associated with the severity of clinical manifestations induced by SARS-CoV-2 infection and likely contribute to the hypercytokinemia, respectively, and likely contribute to the hypercytokinemia (Figure 4E). Especially, the concentration of LTA4H, which is a proinflammatory enzyme which generates the known inflammatory mediator LTB4 and a target to design superior anti-inflammatory drugs, was extremely elevated by $227.7 \%$ in the plasma of ICU patients. Furthermore the virus Spike protein was found to stimulate LTA4H expression in vivo. In addition, the endogenous inhibitor of LTA4H, Spink6 was identified. 
Respiratory failure resulted from acute respiratory distress syndrome (ARDS) is the leading cause of mortality in COVID-1924, 25. Secondary haemophagocytic lymphohistiocytosis (sHLH) is a hyperinflammatory syndrome that is characterized by a fulminant and fatal hypercytokinaemia likely causing multiorgan failure. SHLH is most commonly triggered by viral infections in adults. A profile of increased cytokines such as interleukin (IL) $-2, I L-7$, granulocytecolony stimulating factor, monocyte chemoattractant protein 1 , and TNF-a resembling SHLH is associated with the severity of COVID-19 disease ${ }^{9,24,26-29}$. Recently, a recent retrospective, multicentre study of 150 COVID-19 cases suggests that the mortality is due to virally driven hyperinflammation ${ }^{25}$. All the data indicate hypercytokinaemia is a critically fatal factor in COVID-19 and thus addressing the mechanism causing hypercytokinaemia would provide strategy for the disease treatment.

As a plasma factor with high concentration of $\sim 6-12 \mathrm{M}$, fibrinogen is a known inflammatory mediator containing powerful roles in driving inflammatory responses by influencing multiple aspects of leukocyte and platelet biology to drive thromboinflammatory axis through direct and indirect mechanisms ${ }^{10}$. Recently, we have demonstrated that another plasma factor transferrin with high concentration of 26$52 \mathrm{M}$ acts as an immobilizer of fibrinogen by normally binding to fibrinogen with a molar ratio of $4: 1^{13}$, suggesting that transferrin likely blocks the inflammatory functions of fibrinogen. In this report, we did find that transferrin inhibited the inflammatory response induced by fibrinogen, further confirming transferrin's function as an anti-inflammatory factor. Significant transferrin decrease $(-40.3 \%, 19 \mathrm{M}$ with ability to immobilize only $4.75 \mathrm{M}$ fibrinogen) and fibrinogen increase $(+67.7 \%, 15 \mathrm{M})$ observed in the plasma of the ICU patients likely cause hyperinflammatory responses due to the extreme imbalance between transferrin and fibrinogen.

More importantly, another extreme imbalance between LTA4H (+227.7\%, from 73.24 up to $240 \mathrm{ng} / \mathrm{ml})$ and Spink6 (-25.9\%, from 20.93 down to $15.51 \mathrm{ng} / \mathrm{ml})$ identified as inhibitor of LTA4H here was observed in the plasma of the ICU patients. LTA4H is a pro-inflammatory epoxide hydrolase which catalyzes the conversion of LTA4 to the inflammatory mediator LTB4, which is an inflammatory axis of LTA4-LTA4HLTB4 ${ }^{14}$. As an extremely inflammatory lipid mediator, LTB4 is implicated in many acute and chronic inflammatory diseases in humans ${ }^{15,18-20}$. Leukotrienes are thought to contribute to the airway inflammatory response in bronchiolitis caused by some virus infection ${ }^{30-32}$. LTA4H represents an attractive therapeutic target because it triggers the final critical and rate limited step for LTB4 biosynthesis ${ }^{16}$. These extreme imbalances of fibrinogen and LTA4H, which are two of the most potent inflammatory contributors, and their antagonists of transferrin and Spink6 likely cause excessive inflammatory responses and even hypercytokinemia as observed in the plasma of patients infected by SARS-CoV-2. Interference of these imbalances may provide safe and effective anti-hypercytokinemia strategies.

In this report, we can not completely address the mechanisms to cause the up-regulation of the inflammatory contributors including fibrinogen and LTA4H and to cause the down-regulation of their antagonists including transferrin and Spink6, but at least the partial mechanism has been found here. As 
illustrated in Figure 1C \& 3C, the virus Spike protein showed ability to significantly promote both fibrinogen and LTA4H expression in mice. Given the extreme up-regulation of plasma LTA4H concentration observed in the ICU patients, we suggest that LTA4H-dominantly inflammatory responses induced by Spike protein in severe COVID-19 are critical to cause hypercytokinemia.

Given LTB4 as an extremely inflammatory mediator and LTA4H's key role in LTB4 production, LTA4H inhibition is a potent strategy for the development of anti-inflammatory drugs. Many trials have been actively pursued but very few candidates show clinic efficacy because LTA4H is a bifunctional enzyme containing both epoxide hydrolase and aminopeptidase activity, exerted by two overlapping catalytic sites and those candidates show limited selectivity ${ }^{14}$. LTA4H inhibitors sparing the aminopeptidase activity of the enzyme are speculated as superior and safer drugs. In this report, Spink6 was identified as the first endogenous inhibitor of LTA4H. It selectively inhibited the function epoxide hydrolase without effecting the aminopeptidase activity of the enzyme, providing an excellent candidate and/or template for the development of superior and safer drugs. In addition, Spink6 showed ability to inhibit cytokine secretion induced by products of virus (Spike) and bacteria (LPS) and endogenous inflammatory mediator (fibrinogen and LTA4H), indicating it is also a wide spectrum anti-inflammatory reagent.

\section{Declarations}

\section{Acknowledgments}

This work was supported by the National Science Foundation of China $(31930015,21761142002$, and 331372208), Chinese Academy of Sciences (XDB31000000, KFJ-BRP-008, QYZDJ-SSW-SMC012, and SAJC201606), and Yunnan Province (2015HA023and 2018ZF001) to R. L., as well as the Ministry of Science and Technology of China (2018YFA0801403), National Science Foundation of China(31630075, 31770835, and81770464), Chinese Academy of Sciences (XDA12040221), Youth Innovation Promotion Association (2017432), PLA Youth Talent Project 17QNP010 and Chongqing Health Commission COVID19 Project 2020NCPZX01.

\section{Author contributions}

X. T., M. F., J. Z., Z. L., R. C., K. X., H. Z., J. W., Z. T., G. W., P.M. Z.Z, and J. M. performed the experiments and data analyses; R. L. and G. D. conceived and supervised the project; R. L., X. T., and Q. L. prepared the manuscript. All authors contributed to the discussions.

\section{Conflicts of interest}

The authors declare that they have no conflicts of interest. 
1. Xu, Z., et al. Pathological findings of COVID-19 associated with acute respiratory distress syndrome. Lancet Respir Med (2020).

2. Wu, F., et al. A new coronavirus associated with human respiratory disease in China. Nature 579 , 265269 (2020).

3. Huang, C., et al. Clinical features of patients infected with 2019 novel coronavirus in Wuhan, China. Lancet 395, 497-506 (2020).

4. Wu, Z. \& McGoogan, J.M. Characteristics of and Important Lessons From the Coronavirus Disease 2019 (COVID-19) Outbreak in China: Summary of a Report of 72314 Cases From the Chinese Center for Disease Control and Prevention. JAMA (2020).

5. https://www.who.int/zh/dg/speeches/detail/who-director-general-s-opening-remarks-at-the-missionbriefing-on-covid-19--13-march-2020.

6. https://www.who.int/emergencies/diseases/novel-coronavirus-2019/events-as-they-

7. Channappanavar, R. \& Perlman, S. Pathogenic human coronavirus infections: causes and consequences of cytokine storm and immunopathology. Semin Immunopatho/ 39, 529-539 (2017).

8. Guan, W.J., et al. Clinical Characteristics of Coronavirus Disease 2019 in China. N Engl J Med (2020) DOI:10.1056/NEJMoa2002032.

9. Hirano T, Murakami M. COVID-19: A New Virus, but a Familiar Receptor and Cytokine Release Syndrome. Immunity.2020 Apr 19. pii: S1074-7613(20)30161-8. doi: 10.1016/j.immuni.2020.04.003. [Epub ahead of print]

10. Luyendyk JP, Schoenecker JG, Flick MJ. The multifaceted role of fibrinogen in tissue injury and inflammation. Blood 133, 511-520 (2019).

11. Zhou F, Yu T, Du R, Fan G, Liu Y, Liu Z, Xiang J, Wang Y, Song B, Gu X, Guan L, Wei Y, Li H, Wu X, Xu J, Tu S, Zhang Y, Chen H, Cao B.Clinical course and risk factors for mortality of adult inpatients with COVID-19 in Wuhan, China: a retrospective cohort study.Lancet 395, 1054-1062 (2020).

12. Van Tong H, Van Ba N, Hoan NX, Binh MT, Quyen DT, Son HA, Van Luong H, Quyet D, Meyer CG, Song $\mathrm{LH}$, Toan NL, Velavan TP. Soluble fibrinogen-like protein 2 levels in patients with hepatitis B virusrelated liver diseases.BMC Infect Dis 18, 553 (2018).

13. Tang X, Zhang Z, Fang M, Han Y, Wang G, Wang S, Xue M, Li Y, Zhang L, Wu J, Yang B, Mwangi J, Lu Q, Du X, Lai R.Transferrin plays a central role in coagulation balance by interacting with clotting factors. Cell Res 30, 119-132 (2020).

14. Numao S, Hasler F, Laguerre $C$, Srinivas $H$, Wack N, Jäger P, Schmid A, Osmont A, Röthlisberger $P$, Houguenade J, Bergsdorf C, Dawson J, Carte N, Hofmann A, Markert C, Hardaker L, Billich A, Wolf RM, Penno CA, Bollbuck B, Miltz W, Röhn TA. Feasibility and physiological relevance of designing highly potent aminopeptidase-sparing leukotriene A4 hydrolase inhibitors. Sci Rep 7, 13591 (2017).

15. Dennis, E. A. \& Norris, P. C. Eicosanoid storm in infection and inflammation. Nat Rev Immuno/ 15, 511-523 (2015). 
16. Haeggstrom, J. Z. Leukotriene A4 hydrolase/aminopeptidase, the gatekeeper of chemotactic leukotriene B4 biosynthesis. J Biol Chem 279, 50639-50642 (2004).

17. Meyer-Hoffert U, Wu Z, Kantyka T, Fischer J, Latendorf T, Hansmann B, Bartels J, He Y, Glaser R and Schroder JM. Isolation of SPINK6 in human skin: selective inhibitor of kallikrein-related peptidases. $J$ Biol Chem 285, 32174-32181 (2010)

18. Peters-Golden, M. \& Henderson, W. R. Leukotrienes. N Engl J Med 357, 1841-1854 (2007).

19. Di Gennaro, A. \& Haeggstrom, J. Z. The leukotrienes: immune-modulating lipid mediators of disease. Adv Immuno/ 116, 51-92(2012).

20. Di Gennaro, A. \& Haeggstrom, J. Z. Targeting leukotriene B4 in inflammation. Expert Opin Ther Targets 18, 79-93 (2014).

21. Haeggstrom, J. Z. Leukotriene A4 hydrolase and the committed step in leukotriene B4 biosynthesis. Clin Rev Allergy Immunol 17,111-131 (1999)

22. VanderMeer, T. J. et al. Acute lung injury in endotoxemic pigs: role of leukotriene B4. J Appl Physiol (1985) 78, 1121-1131, doi:10.1152/jappl.1995.78.3.1121 (1995).

23. Xiao, Q. et al. Bufexamac ameliorates LPS-induced acute lung injury in mice by targeting LTA4H. Sci Rep 6, 25298, doi:10.1038/srep25298 (2016).

24. Mehta P, McAuley DF, Brown M, Sanchez E, Tattersall RS, Manson JJ; HLH Across Speciality Collaboration, UK. COVID-19: consider cytokine storm syndromes and immunosuppression. Lancet 395,1033-1034 (2020).

25. Ruan Q, Yang K, Wang W, Jiang L, Song J. Clinical predictors of mortality due to COVID-19 based on an analysis of data of 150 patients from Wuhan, China. Intensive Care Med 2020; published online March 3. DOI:10.1007/s00134-020-05991-x.

26. Ramos-Casals M, Brito-Zeron P, Lopez-Guillermo A, Khamashta MA, Bosch X. A dult haemophagocytic syndrome. Lancet 383, 1503-16 (2014).

27. Seguin A, Galicier L, Boutboul D, Lemiale V, Azoulay E. Pulmonary involvement in patients with hemophagocytic lymphohistiocytosis. Chest 149, 1294-301 (2016).

28. Huang C, Wang Y, Li X, et al. Clinical features of patients infected with 2019 novel corona virus in Wuhan, China. Lancet 395,497-506 (2020).

29. Russell CD, Millar JE, Baillie JK. Clinical evidence does not support corticosteroid treatment for 2019nCoV lung injury. Lancet 395, 473-75 (2020).

30. Da Dalt L, Callegaro S, Carraro S, Andreola B, Corradi M, Baraldi E. Nasal lavage leukotrienes in infants with RSV bronchiolitis. Pediatr Allergy Immuno/ 18,100-4 (2007).

31. Sznajer Y, Westcott JY, Wenzel SE, Mazer B, Tucci M, Toledano BJ. Airway eicosanoids in acute severe respiratory syncytial virus bronchiolitis. J Pediatr145,115-8 (2004).

32. Jones A, Qui JM, Bataki E, Elphick H, Ritson S, Evans GS, Everard ML. Neutrophil survival is prolonged in the airways of healthy infants and infants with RSV bronchiolitis. Eur Respir $\mathrm{J}$ 20, 651-7 (2002). 
Figures
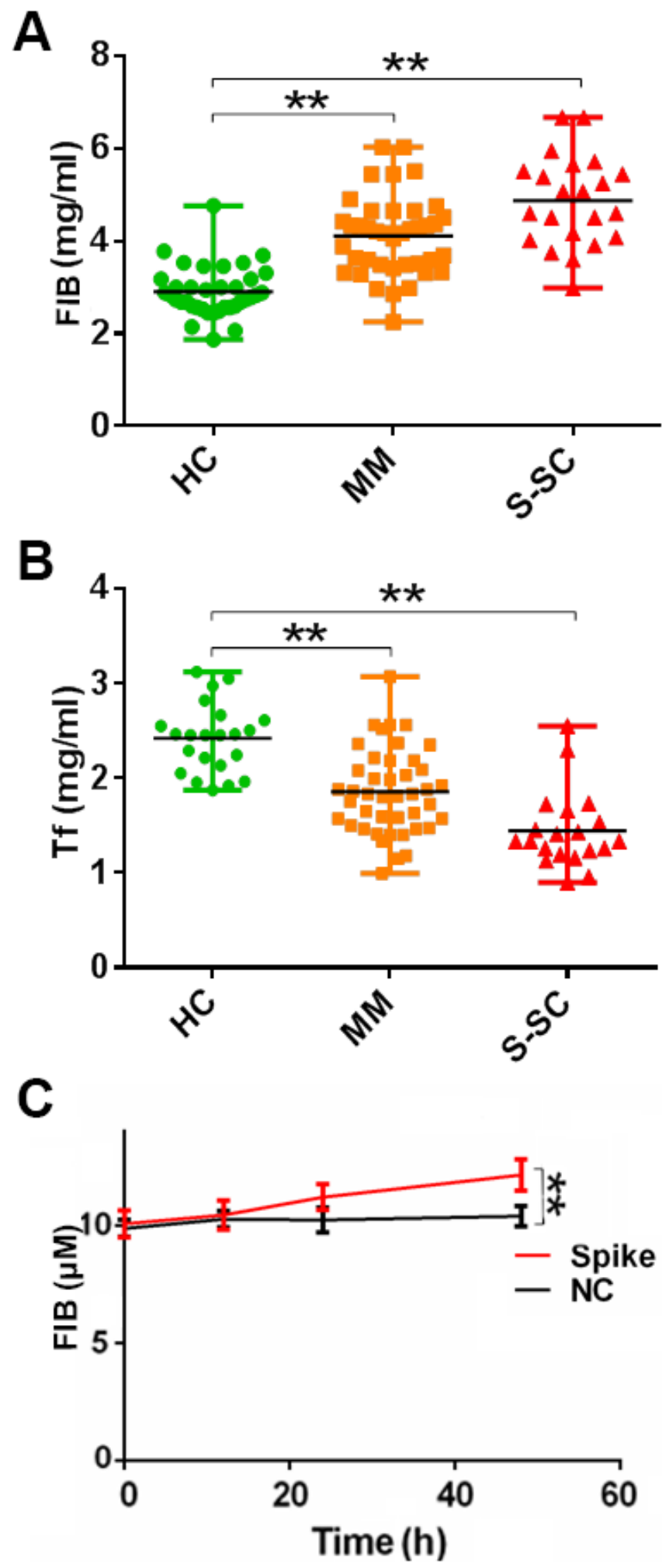

\section{Figure 1}

Increased fibrinogen and decreased transferrin level in patients infected by SARS-CoV-2. Concentrations of fibrinogen (A) and transferrin (B) in plasma from patients infected by SARS-CoV-2 who had been admitted to intensive care unit (ICU) (S-SC), non-ICU patients (MM), and healthy control (HC) were 
determined. Data represent mean \pm SD $(n=20-43),{ }^{* \star} p<0.01$ by $(A$ and $B)$ unpaired $t$-test. (C) Concentration of fibrinogen in the plasma of mice after Spike $(40 \mu \mathrm{g} / \mathrm{kg}$, intravenous injection) stimulation was determined by ELISA. Data represent mean \pm SD $(n=6),{ }^{\star \star} p<0.01$ by (C) unpaired t-test. Tf: transferrin; FIB: fibrinogen.

A
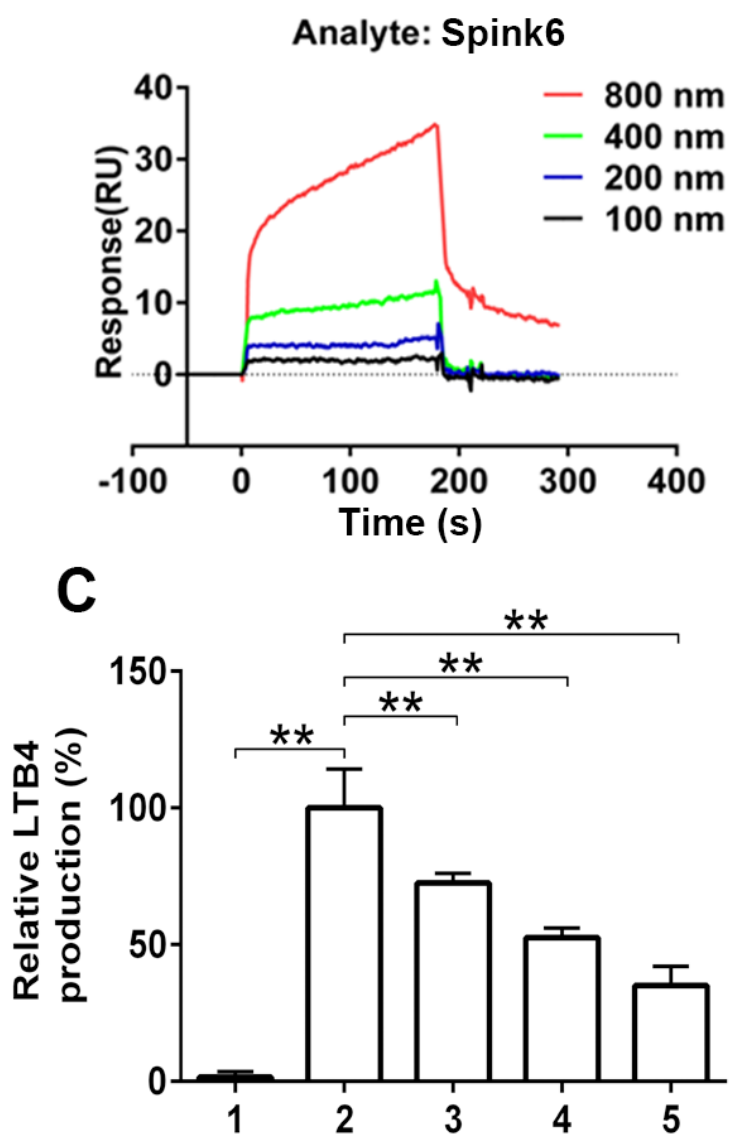

$\mathbf{E}$

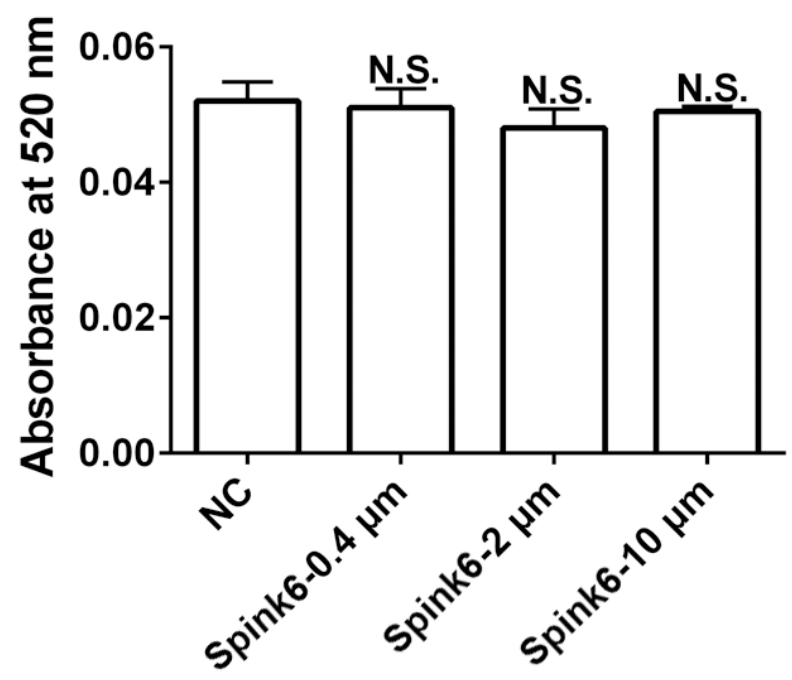

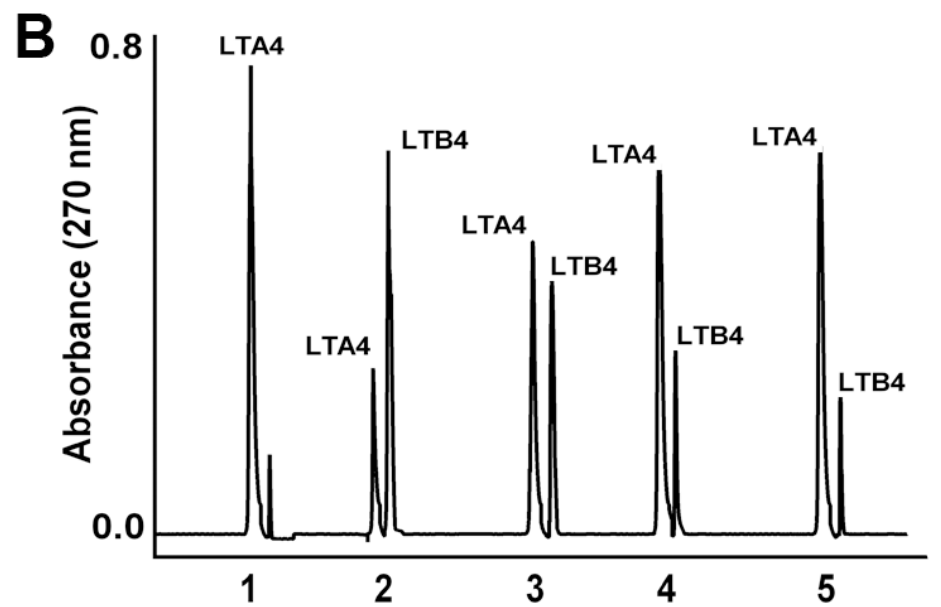

D

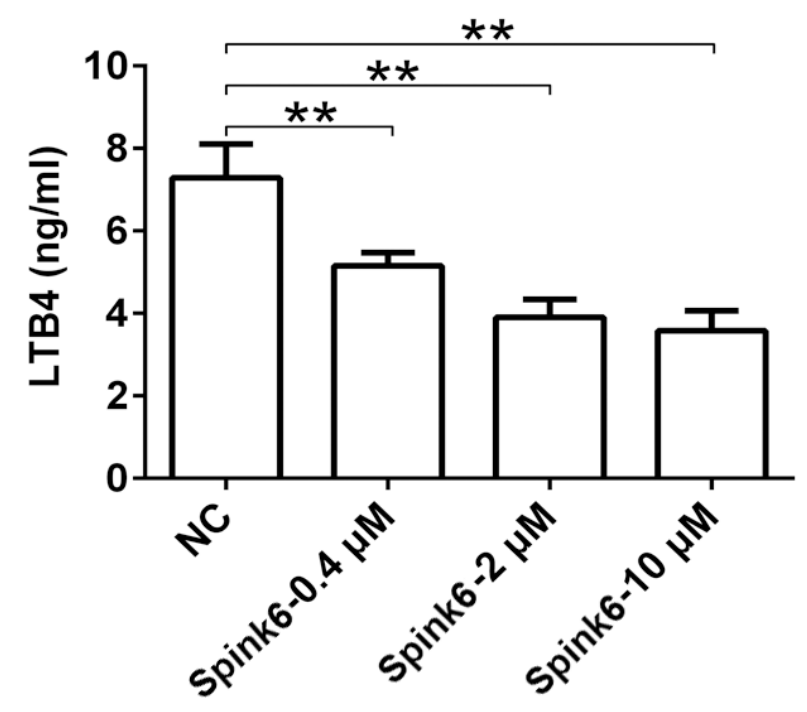

Figure 2 
Spink6 specifically inhibits epoxide hydrolase activity of LTA4H without effecting aminopeptidase activity. (A) SPR analysis of the interaction between Spink6 and LTA4H. Representative RP-HPLC analysis (B) and quantification (C) of LTB4 released from $10 \mu \mathrm{g}$ of LTA4 methyl ester hydrolyzed by $100 \mathrm{nM}$ LTA4H mixed with $0,0.4,2$, or $10 \mu \mathrm{M}$ Spink6 (panel 2-5), respectively. The LTB4 production in "A" was also tested by LTB4 ELISA kit (D). (E) Effect of Spink6 on aminopeptidase activity of LTA4H was assayed by ninhydrin color development method. Data represent mean \pm SD of five independent experiments, ${ }^{*} \mathrm{p}<$ 0.01 by one-way ANOVA with Dunnett's post hoc test. N.S.: no significance.

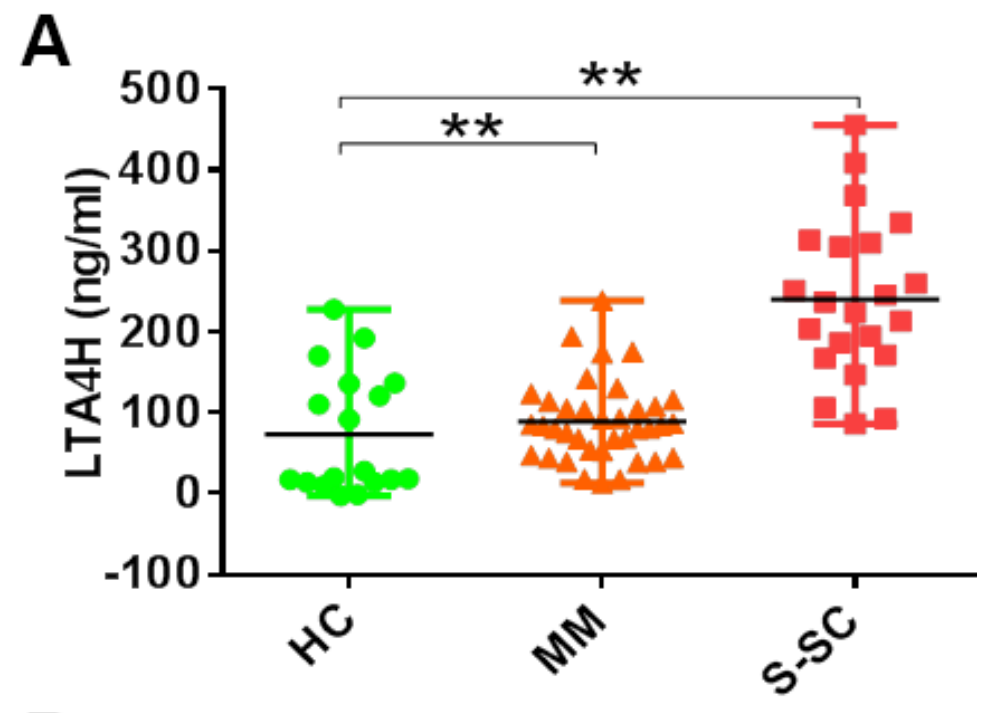

B

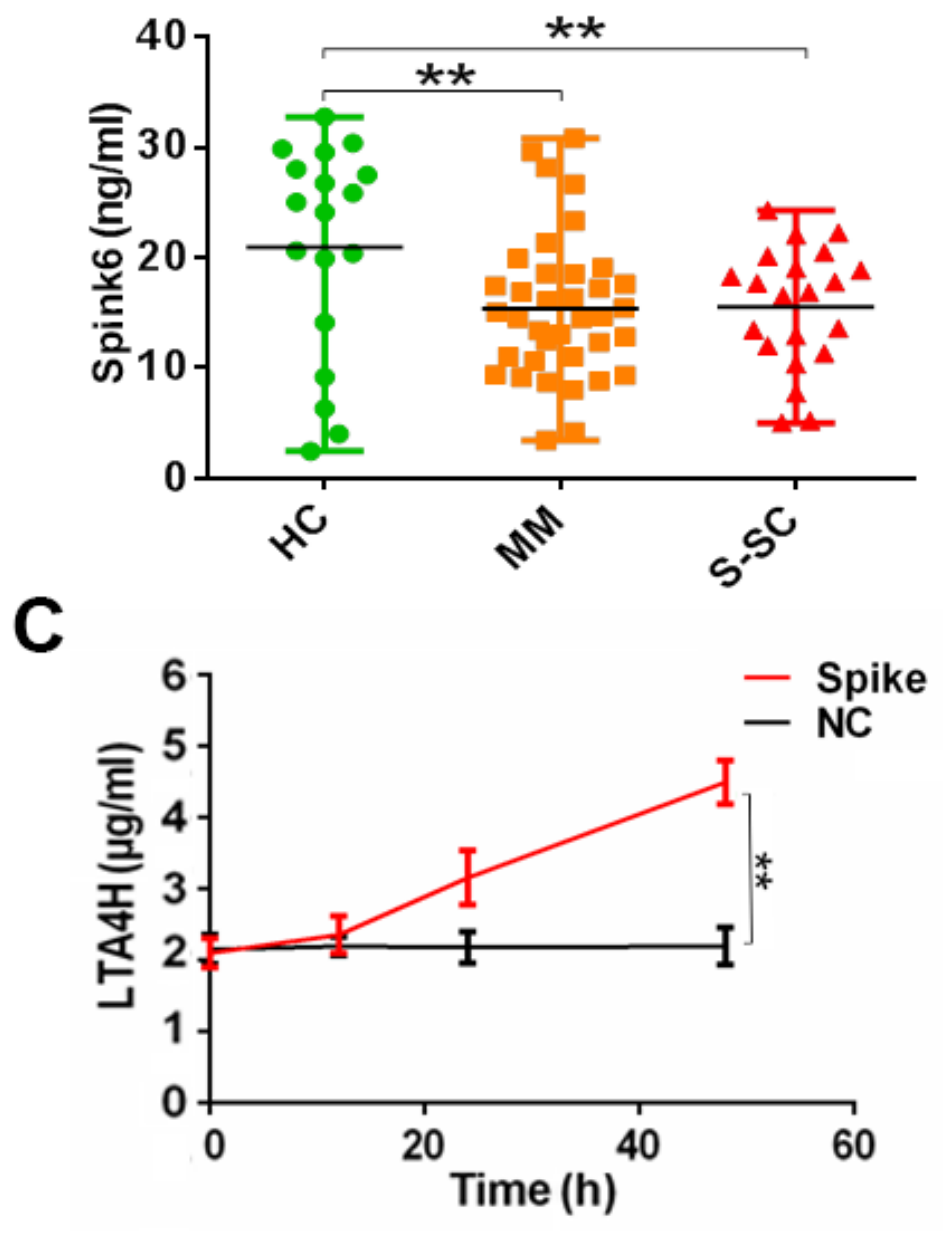


Figure 3

Increased LTA4H and decreased Spink6 level in patients infected by SARS-CoV-2. Concentrations of LTA4H (A) and Spink6 (B) in plasma from patients infected by SARS-CoV-2 who had been admitted to intensive care unit (ICU) (S-SC), non-ICU patients (MM), and healthy control (HC) were determined. Data represent mean $\pm S D(n=18-37)$, ${ }^{\star \star} p<0.01$ by $(A$ and $B)$ unpaired $t$-test. (C) Concentration of LTA4H in the plasma of mice after Spike ( $40 \mu \mathrm{g} / \mathrm{kg}$, intravenous injection) stimulation was determined by ELISA. Data represent mean $\pm \operatorname{SD}(n=6), * \star p<0.01$ by $(C)$ unpaired t-test.

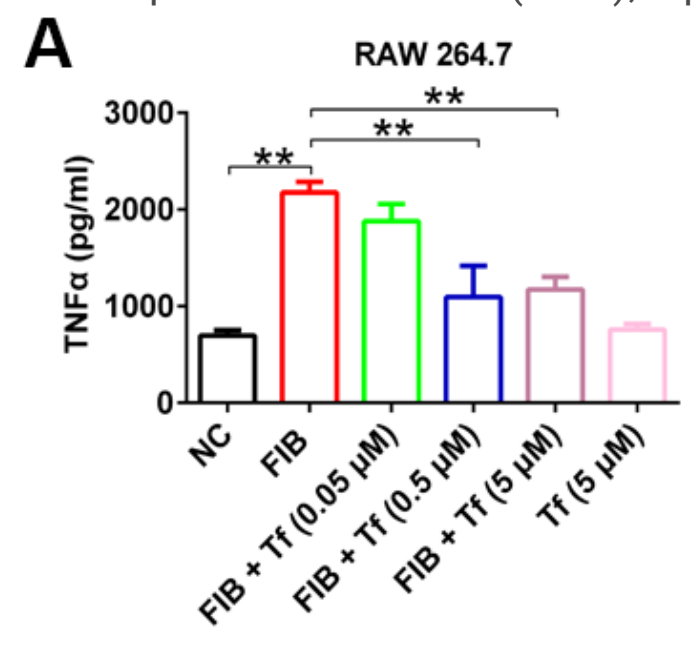

C
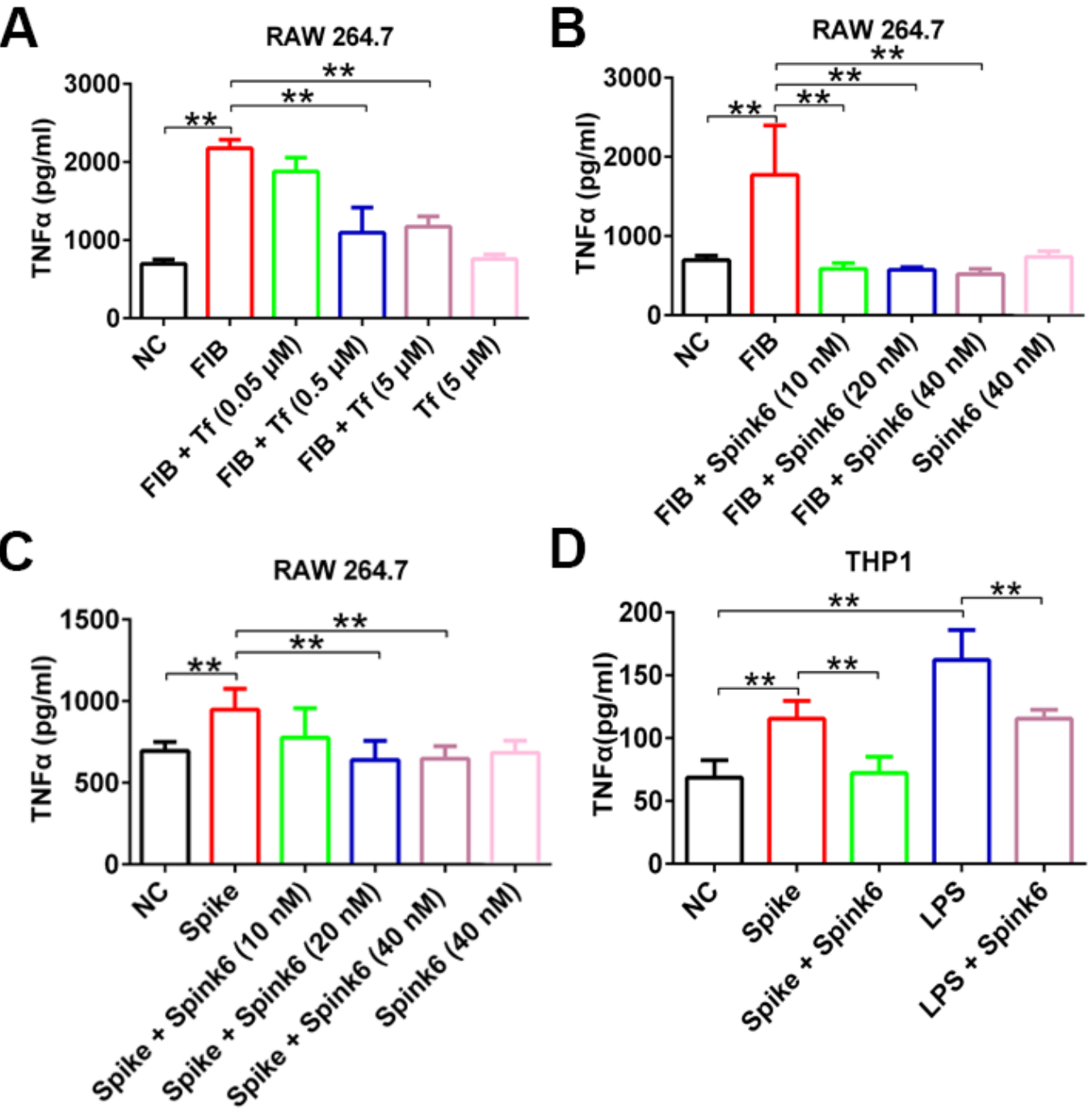

D

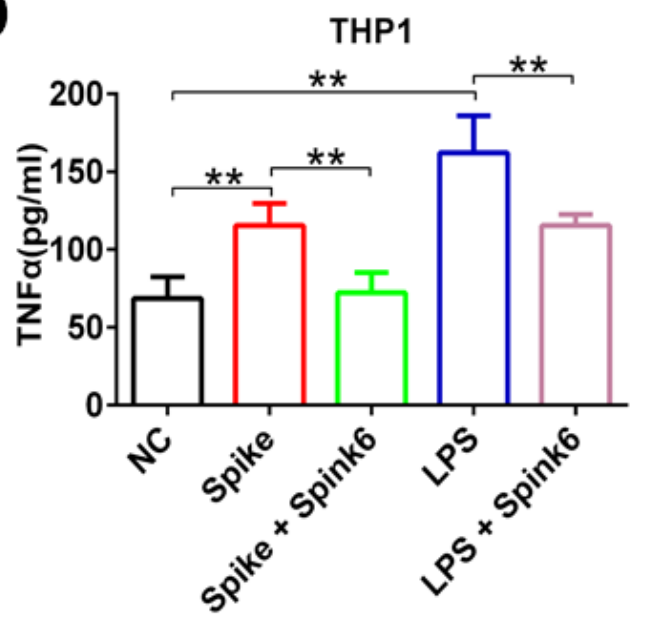

E

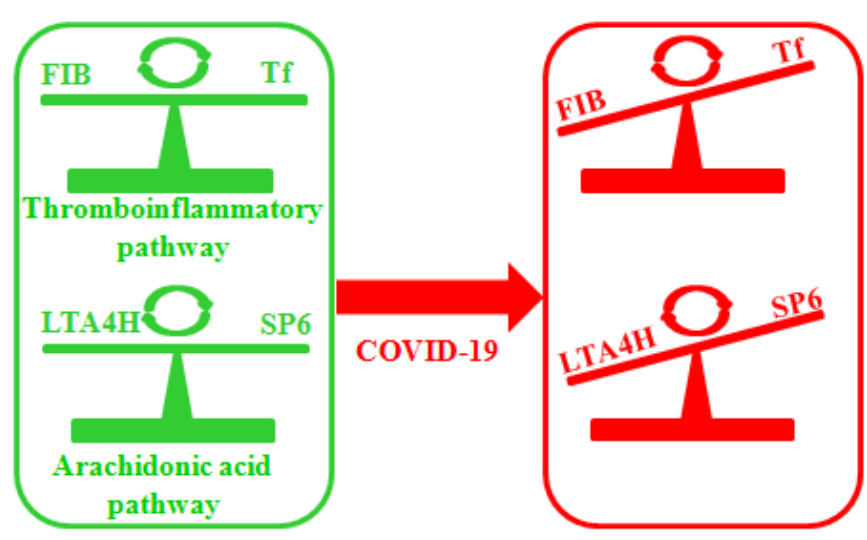

Normal

Hypercytokinemia 


\section{Figure 4}

Effects of transferrin or Spink6 on TNF-a secretion induced by fibrinogen or Spike. RAW264.7 cells were stimulated by fibrinogen for $16 \mathrm{~h}$ in presence or absence of transferrin (A) or Spink6 (B). Supernatant level of TNF-a was measured by using ELISA kit. (C) RAW264.7 cells were stimulated by Spike for $16 \mathrm{~h}$ in presence or absence of Spink6. Supernatant level of TNF-a was measured by using ELISA kit. (D) THP-1 cells were stimulated by Spike or LPS for $12 \mathrm{~h}$ in presence or absence of Spink6. Supernatant level of TNF-a was measured using ELISA kit. (E) Graphical representation of imbalance between two of the most potent inflammatory drivers (fibrinogen (FIB) and LTA4H) and their antagonists (transferrin (Tf) and Spink6 (SP6)) possibly causes hypercytokinemia in COVID-19. Data represent mean \pm SD of five independent experiments, ${ }^{* *} p<0.01$ by one-way ANOVA with Dunnett's post hoc test.

\section{Supplementary Files}

This is a list of supplementary files associated with this preprint. Click to download.

- Supplementaryinformation.pdf 